\title{
Associations of psychosis-risk symptoms with quality of life and self-rated health in the Community
}

\author{
Chantal Michel ${ }^{\mathrm{a}, *, 1}$, Stefanie J. Schmidt ${ }^{\mathrm{a}, \mathrm{b}, 1}$, Nina Schnyder ${ }^{\mathrm{a}, \mathrm{c}, \mathrm{d}}$, Rahel Flückiger ${ }^{\mathrm{a}}$, \\ Iljana Käufeler ${ }^{\mathrm{a}}$, Benno G. Schimmelmann ${ }^{\mathrm{a}, \mathrm{e}}$, Frauke Schultze-Lutter ${ }^{\mathrm{f}}$ \\ a University Hospital of Child and Adolescent Psychiatry and Psychotherapy, University of Bern, Bern, Switzerland \\ ${ }^{\mathrm{b}}$ Department of Clinical Psychology and Psychotherapy, University of Bern, Bern, Switzerland \\ ' School of Public Health, The University of Queensland, Brisbane, Australia \\ d Policy and Epidemiology Group, Queensland Centre for Mental Health Research, Brisbane, Australia \\ e University Hospital of Child and Adolescent Psychiatry, University Hospital Hamburg-Eppendorf, Hamburg, Germany \\ ${ }^{\mathrm{f}}$ Department of Psychiatry and Psychotherapy, Medical Faculty, Heinrich-Heine-University Düsseldorf, Düsseldorf, Germany
}

\section{A R T I C L E I N F O}

\section{Article history:}

Received 18 February 2019

Received in revised form 12 August 2019

Accepted 26 August 2019

Available online 3 October 2019

\section{Keywords:}

Quality of life

Health status

General population

Psychosis risk

Mental disorders

\begin{abstract}
A B S T R A C T
Background: Understanding factors related to poor quality of life (QoL) and self-rated health (SRH) in clinical high-risk (CHR) for psychosis is important for both research and clinical applications. We investigated the associations of both constructs with CHR symptoms, axis-I disorders, and sociodemographic variables in a community sample.

Methods: In total, 2683 (baseline) and 829 (3-year follow-up) individuals of the Swiss Canton of Bern (age-at-baseline: 16-40 years) were interviewed by telephone regarding CHR symptoms, using the Schizophrenia Proneness Instrument for basic symptoms, the Structured Interview for Psychosis-Risk Syndromes for ultra-high risk (UHR) symptoms, the Mini-International Neuropsychiatric Interview for current axis-I disorders, the Brief Multidimensional Life Satisfaction Scale for QoL, and the 3-level EQ-5D for SRH.

Results: In cross-sectional structural equation modelling, lower SRH was exclusively significantly associated with higher age, male gender, lower education, and somatoform disorders. Poor QoL was exclusively associated only with eating disorders. In addition, both strongly interrelated constructs were each associated with affective, and anxiety disorders, UHR and, more strongly, basic symptoms. Prospectively, lower SRH was predicted by lower education and anxiety disorders at baseline, while poorer QoL was predicted by affective disorders at baseline.

Conclusions: When present, CHR, in particular basic symptoms are already distressful for individuals of the community and associated with poorer subjective QoL and health. Therefore, the symptoms are clinically relevant by themselves, even when criteria for a CHR state are not fulfilled. Yet, unlike affective and anxiety disorders, CHR symptoms seem to have no long-term influence on QoL and SRH.
\end{abstract}

(c) 2019 Elsevier Masson SAS. All rights reserved.

\section{Introduction}

Psychoses, in particular schizophrenia, are highly disabling disorders and associated with poor quality of life (QoL) and low self-rated health (SRH) [1]. QoL, the overall general, subjective evaluation of life as good and satisfactory, has been increasingly considered as an important treatment target [2,3] for being an

\footnotetext{
* Corresponding author at: University Hospital of Child and Adolescent Psychiatry and Psychotherapy, University of Bern, Bolligenstrasse 111, Haus A, 3000, Bern 60, Switzerland.

E-mail address: chantal.michel@upd.unibe.ch (C. Michel).

1 shared first-authorship
}

important predictor of functional outcomes in first-episode [4] and chronic [5,6] psychosis. Furthermore, poor QoL in psychosis patients was associated with more severe depressive, positive and negative symptoms, and comorbid personality disorder [7,8]. In doing so, impairment of QoL may ameliorate across early stages of psychosis, with worse QoL in clinical high risk (CHR) and first-episode psychosis compared to chronic schizophrenia $[9,10,11]$, likely as a result of adaption to the illness over time and loss of insight, which commonly increases over the course of the illness [9,12,13].

Besides QoL, SRH is another important subjective construct to rate individuals' current health status, both physical and mental $[14,15]$. SRH has been used as a reliable, quick assessment for population health monitoring [16], and frequently studied by epidemiologists in relation to mortality, morbidity, disability, and 
psychopathological symptom severity $[17,18]$. For psychosis, esp. schizophrenia patients, high rates of poor physical health and premature mortality along with a substantially reduced average life expectancy $[19,20]$ and, in comparison to mentally healthy controls, reduced SRH were reported [21].

The majority of first-episode psychotic disorders are preceded by a prodromal phase in which a multitude of CHR symptoms, other mental health problems, psychosocial deficits, and, already, a reduction in QoL and SRH occur, and during which help may be sought [22-25]. This phase offers an excellent starting point for an indicated prevention that, currently, aims at reducing $\mathrm{CHR}$ symptoms and, thereby, preventing transition to frank psychosis [26]. Currently, two major sets of CHR criteria are used to detect a putatively psychosis-prodromal phase: (i) symptomatic ultra-high risk (UHR) criteria, i.e., attenuated (APS) or brief intermittent psychotic symptoms (BIPS); and (ii) basic symptom criteria, i.e., Cognitive Disturbances (COGDIS) and Cognitive-Perceptive Basic Symptoms (COPER), including subjective disturbances in thought and perception processes [22,24].

A recent meta-analysis found that the CHR state is also characterised by consistent and large impairments in QoL, compared to healthy controls $[10,24,27]$ and other help seekers [28], that are independent of a transition to psychosis and as severe as QoL impairments in other psychiatric disorders [6,24]. Similar to psychosis patients, the association between QoL and psychopathology in CHR patients was related to the severity of both positive symptoms and unspecific, especially depressive symptoms, which were the most important predictors of poor QoL in CHR states $[10,11,29]$. Furthermore, anxiety symptoms, cognitive impairments [29], and poor functioning were also related to poor QoL in CHR states [24,29].

Low SRH, i.e., poor physical health and an unhealthy lifestyle, are common in UHR patients and should be monitored regularly $[30,31]$. In recent community studies, the presence of psychotic experiences was associated with poorer SRH [32]. However, compared to research on QoL, little is known about factors influencing SRH and whether differential associations between these factors, CHR, and QoL/SRH exist. Moreover, the effect of UHR and basic symptoms on QoL and SRH has only cursory been investigated and only in clinical samples.

Therefore, the present study of QoL and SRH in a community sample investigated the relative contribution of their potential sociodemographic (age, gender, education) and clinical predictors (presence of non-psychotic axis-I disorders, UHR and basic symptoms), using both cross-sectional and longitudinal data. We used structural equation modelling(SEM) to simultaneously account for potential interrelations between all variables and outcomes [33]. We hypothesised that sociodemographic variables would play a minor role, while clinical variables, particularly affective and anxiety disorders, would have the strongest association with both QoL and $\mathrm{SRH}$. For the assumed influence of insight on QoL in psychosis and because basic symptoms are experienced with immediate full insight into their abnormal nature by definition, we further assumed that, compared to UHR symptoms, basic symptoms would have a stronger negative effect on QoL and SRH.

\section{Methods}

\subsection{Sample}

The sample consisted of participants in the baseline and followup assessments of the 'Bern Epidemiological At-Risk' (BEAR) study [34], a representative random sample of the Bernese general population (see also eTexts 1 and 2). At baseline, a stratified sampling method was used to obtain a representative sample from the approximately 310,000 predominantly Caucasian individuals aged 16-40 years, registered in the semi-rural Canton Bern. The age range was selected because most first-episodes of affective and non-affective psychoses are reported to occur between 17 and 41 years of age [35,36]. Participants were first recruited from 06/2011 to $11 / 2014(\mathrm{~N}=2683$, response rate: $63.4 \%)$; a subsample of participants with CHR symptoms and age- and gender-matched controls was re-contacted from 06/2015 to 03/2018 (median follow-up 39 months, $\mathrm{N}=829$, response rate: $66.4 \%$ ) and assessed using the Computer-Assisted Telephone Interviewing technique [34]. The ethics committee of the University of Bern approved both studies; participation in the telephone interview equalled informed consent. Interviews were aborted prematurely when respondents had (i) a lifetime diagnosis of psychosis [37] or (ii) insufficient language skills in German, French, or English. The semi-structured interviews lasted $43 \mathrm{~min}$ on average (SD: $20 \mathrm{~min}$; range: $20-225 \mathrm{~min}$ ).

\subsection{Assessments}

\subsubsection{Assessment of mental disorders}

Present DSM-IV non-substance-related axis-I disorders including affective, anxiety, eating, somatoform, obsessive-compulsive and post-traumatic stress disorder were assessed using the MiniInternational Neuropsychiatric Interview (M.I.N.I.) [38], which had been previously applied successfully in telephone interviews of community samples [38]. The M.I.N.I. demonstrated good reliability, and good concurrent and predictive validity for assessing axis-I disorders [39].

\subsubsection{Assessment of CHR symptoms}

CHR symptoms and criteria (see eTable 1) were assessed using semi-structured interviews with good interrater reliability [40,41]: the Structured Interview for Psychosis-Risk Syndromes (SIPS, version 5.0) [41] for UHR symptoms and criteria, i.e. APS and the APS criterion, and psychotic symptoms and the BIPS criterion and the Schizophrenia Proneness Instrument, Adult version (SPI-A) [40] for predictive basic symptoms and related criteria, i.e. COPER and COGDIS [22]. Strictly, the definition of basic symptoms includes the requirement that the phenomenon in question presents a deviation from the 'normal' self. Nevertheless, the SPI-A also allows the rating of lifelong persistent complaints (i.e., ' 7 '='has always been present in the same severity (trait)'); that, however, is not considered a basic symptom. The genetic riskfunctional decline criterion was estimated only with a first-degree relative of psychosis serving as a genetic risk factor and being assessed with the SIPS; schizotypal personality disorder was not assessed because of the lack of an informant. The genetic riskfunctional decline criterion was never met [34].

For the present analyses, CHR symptoms were defined by the presence of any one APS, BIPS, and/or basic symptom at baseline, irrespective of the onset/worsening and/or frequency requirements of related CHR criteria. CHR symptoms were only rated if the phenomenon in question was not fully and better explained by another non-psychotic disorder or psychotropic drug use [22,41].

\subsubsection{Assessment of quality of life and self-rated health}

The Brief Multidimensional Life Satisfaction Scale (BMLSS) [42] was used to assess QoL, which demonstrated good psychometric properties and can be regarded as a brief, reliable, and valid measure of QoL [42]. The BMLSS assesses satisfaction in eight different life domains that are rated on a seven-point Likert-type scale ranging from 'horrible' $=0$ to 'very happy' $=6$. The eight-item BMLSS has a single-factor structure and addresses four main dimensions: intrinsic (myself, life in general), social (friendships, family life), external (work, housing), and perspective (finances, future) [42]. 
The three-level version of the EuroQoL-5D (EQ-5D-3 L) was used to assess SRH [14]. An extensive body of literature supports the validity and reliability of the EQ-5D-3 L in various conditions and populations [43]. The EQ-5D-3 L comprises five items: mobility, self-care, usual activities, pain/discomfort, and anxiety/ depression. Each item is rated on three levels: no, some, and extreme problems. We calculated an EQ-5D-3 L summary score according to Hinz et al. [44] (100-(10x [value1+value2+value3 +value4+value5-5])). An additional analogue scale records participants own judgements on their current health from 'worst imaginable health state' $(0)$ to 'best imaginable health state' (100).

\subsubsection{Quality assurance}

Satisfying reliability of telephone assessments compared with face-to-face ones was demonstrated for mental disorders and CHR symptoms $[45,46]$. To achieve a $\geq 95 \%$ concordance rate with the trainers, both experts in the early detection of psychosis (F.S.-L. and C.M.), interviewers (all clinical psychologists) received intensive 3month training, especially in the semi-structured, contextdependent assessment of CHR symptoms and mental disorders. Additionally, weekly supervision of all symptom ratings with the interviewers was performed by the two trainers to guarantee excellent, valid, and reliable data quality.

\subsection{Statistical analyses}

Differences in non-normally distributed continuous and ordinal data were assessed using the Wilcoxon Signed Ranked Test to compare QoL and SRH at baseline and follow-up. Prior to SEM, we computed orthogonal confirmatory factor analyses (CFA) with varimax rotation based on polychoric correlation matrices for $\mathrm{QoL}$ and SRH, to assure that both latent factors (i.e., QoL and SRH) were assessed reliably. We performed SEM with the weighted least squares and variance adjusted estimator (WLSMV) [47] based on diagonally weighted least squares (DWLS) for categorical and ordinal variables [48]. Missing data were deleted listwise $(0.3 \%$ missing data in the cross-sectional and $0.2 \%$ in the longitudinal analyses). We assessed the model fit with five commonly used indices, as follows: the $\chi^{2}$ test, comparative fit index (CFI), TuckerLewis index (TLI), standardised root mean square residual (SRMR), and root-mean-square error of approximation (RMSEA) including $90 \%$-confidence interval ( $90 \% \mathrm{CI})$. A non-significant $\chi^{2}$-test,
$\mathrm{CFI} \geq 0.95, \quad \mathrm{TLI} \geq 0.95, \quad \mathrm{SRMR}<0.08$, and $\mathrm{RMSEA}<0.06(90 \% \mathrm{CI}$ should not contain 0.08 ) indicate good model fit $[49,50]$. In the evaluation of model fit, we focussed on CFI, TLI, SRMR, and RMSEA, because the $\chi^{2}$-test is sensitive to sample size, usually resulting in model rejection in large samples such as ours [51].

Using cross-sectional baseline data, we first tested the hypothesised model including all associations between the predictors (modelled as manifest variables) and both QoL and SRH (modelled as two correlated latent variables; see eFig. 1). Covariates were allowed to covary with each other. Afterwards, we dropped non-significant associations from the model. For the prospective data, we used QoL and SRH assessed at follow-up as latent outcome variables and repeated these steps. Statistical analyses were conducted using SPSS 24.0 (Stata Corporation, College Station, TX, USA) and the lavaan package for R (R Core Team) [52].

\section{Results}

Table 1 shows the clinical and sociodemographic characteristics of the baseline sample $(\mathrm{N}=2683)$. Comparisons between baseline and follow-up did not reveal a significant difference in SRH (Table 2), yet slightly higher intrinsic and perspective BMLSS scores at follow-up with small effect sizes (Table 2).

The initial cross-sectional model had a good model fit (eFig. 2, eTable 2), maintained after the elimination of nine insignificant paths (Fig. 1). In the final cross-sectional model, lower SRH had significant associations with older age, male gender, lower education, any affective disorder, any anxiety disorder, any somatoform disorder, and both UHR and basic symptoms; while lower QoL was significantly associated with any affective disorder, any anxiety disorder, any eating disorder, and both UHR and basic symptoms. Its clinical and sociodemographic predictors were significantly correlated with each other, though effects were commonly small (Table 3 ). Of the sociodemographic predictors, female gender had the strongest association with clinical variables (any anxiety disorder, any eating disorder, any somatoform disorder and UHR symptoms); while higher education was associated with both UHR and basic symptoms. Older age was exclusively associated with presence of basic symptoms (Table 3).

The initial longitudinal model demonstrated a good fit to the data (eFigure 3, eTable 3), which improved further after the

Table 1

Sociodemographic and clinical characteristics of the sample at baseline $(\mathrm{N}=2,683)$

\begin{tabular}{|c|c|c|}
\hline & $\mathrm{N}$ & $\%$ \\
\hline Age (mean $\pm S D$, median, range) & $30.7 \pm 7.6,33.0,15.3-41.5$ & \\
\hline Gender (male) & 1447 & 53.9 \\
\hline Nationality (Swiss) & 2512 & 93.6 \\
\hline \multicolumn{3}{|l|}{ Highest education } \\
\hline Primary school or school for special needs (6 school years) & 35 & 1.3 \\
\hline Secondary school (9-10 school years) & 1602 & 59.7 \\
\hline High school (12-13 school years) & 1046 & 39.0 \\
\hline SOFAS score (mean \pm SD, median, range) & $85.3 \pm 7.1,87.0,39-99$ & \\
\hline Any current axis-I disorder ${ }^{*}$ & 353 & 13.2 \\
\hline Any affective disorder & 112 & 4.2 \\
\hline Any anxiety disorder & 252 & 9.4 \\
\hline Any eating disorder & 12 & 0.4 \\
\hline Any somatoform disorder & 27 & 1.0 \\
\hline An obsessive-compulsive disorder & 21 & 0.8 \\
\hline A posttraumatic stress disorder & 19 & 0.7 \\
\hline Any current CHR symptom ${ }^{*}$ & 370 & 13.7 \\
\hline Any current APS (score 3-5) & 200 & 7.5 \\
\hline Any current BIPS (score 6 ) & 3 & 0.1 \\
\hline Any current basic symptom (excl. traits) & 264 & 9.8 \\
\hline
\end{tabular}

Note: CHR: clinical high risk; APS: attenuated psychotic symptoms; BIPS: brief intermittent psychotic symptoms.

An overlap between CHR symptoms and any current axis-I disorder was found for $n=116$ (4.3\%).Source: Bern Epidemiological At Risk (BEAR) Study (SNF project number: $135,381)$. 
Table 2

Comparison of quality of life scores of the sample at baseline $(\mathrm{N}=2683)$ and at follow-up $(\mathrm{n}=829)$.

\begin{tabular}{|c|c|c|c|}
\hline & $\begin{array}{l}\text { Baseline }(\mathrm{N}=2683) \text { mean } \pm S D \text {, } \\
\text { median, range }\end{array}$ & $\begin{array}{l}\text { Follow-up }(\mathrm{n}=829) \text { mean } \pm S D \text {, } \\
\text { median, range }\end{array}$ & $\begin{array}{l}\text { Statistics Wilcoxon Signed Rank Test Z, p, } \\
\text { Rosenthal's } r^{\mathrm{a}}\end{array}$ \\
\hline \multicolumn{4}{|l|}{ Self-rated health } \\
\hline $\begin{array}{l}\text { Visual analogue scale score of the EQ- } \\
5 \mathrm{D}-3 \mathrm{~L}\end{array}$ & $83.81 \pm 12.75,85.0,3-100$ & $83.80 \pm 12.88,85.0,10-100$ & $Z=-1.541, p=0.123, r=-0.054$ \\
\hline $\begin{array}{l}\text { Index value score of the EQ-5D-3L } \\
\text { Quality of life }\end{array}$ & $96.91 \pm 7.07,100.0,40-100$ & $96.54 \pm 7.77,100.0,40-100$ & $Z=-0.796, p=0.426, r=-0.028$ \\
\hline BMLSS intrinsic & $9.85 \pm 1.42,10.0,0-12$ & $9.97 \pm 1.36,10.0,3-12$ & $\mathrm{Z}=-3.227, \mathrm{p}=0.001, r=-0.112$ \\
\hline BMLSS social & $10.4 \pm 1.43,11.0,0-12$ & $10.4 \pm 1.48,11.0,3-12$ & $\mathrm{Z}=-1.053, \mathrm{p}=0.292, r=-0.037$ \\
\hline BMLSS external & $9.60 \pm 1.79,10.0,0-12$ & $9.71 \pm 1.80,10.0,2-12$ & $\mathrm{Z}=-1.741, \mathrm{p}=0.082, r=-0.061$ \\
\hline BMLSS perspective & $9.40 \pm 1.70,10.0,0-12$ & $9.65 \pm 1.67,10.0,1-12$ & $Z=-3.752, p \leq 0.001, r=-0.131$ \\
\hline
\end{tabular}

Note: EQ-5D-3L: 3-level version of EQ-5D; BMLSS: Brief Multidimensional Life Satisfaction Scale.

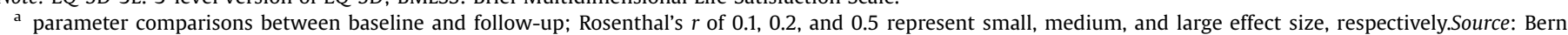
Epidemiological At Risk (BEAR) Study (SNF project number: 135,381 and 155,951).

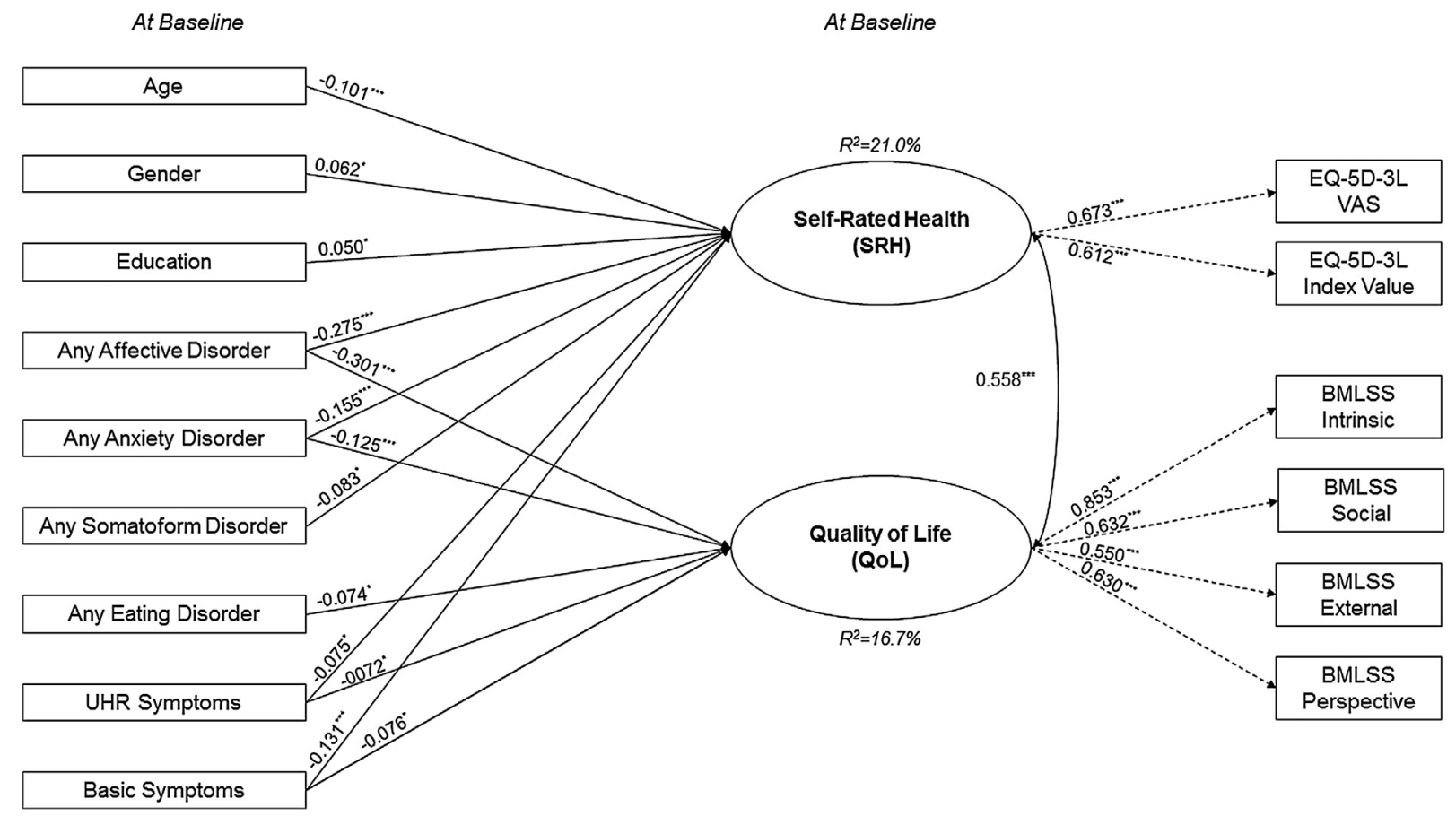

Fig. 1. Results of the trimmed model with non-significant associations removed for the cross-sectional data $(\mathrm{n}=2683)$.

Model fit indices: $\chi_{(49)}^{2}=109.251, \mathrm{p}<0.001 ; \mathrm{CFI}=0.979 ; \mathrm{TLI}=0.971 ; \mathrm{SRMR}=0.024$; RMSEA $=0.021(90 \% \mathrm{CI}=0.016-0.027)$.

Explained variance $\left(\mathrm{R}^{2}\right)$ for each endogenous variable in italics.

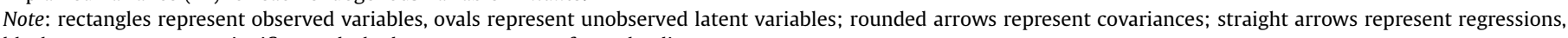
black arrows represent significant; dashed arrows represent factor loadings.

UHR: ultra-high risk; EQ-5D-3L: 3-level version of the EQ-5D; BMLSS: Brief Multidimensional Life satisfaction Scale.

elimination of sixteen insignificant paths (Fig. 2). In the final longitudinal model, lower SRH at follow-up was significantly predicted by lower education and any anxiety disorder at baseline, while lower QoL at follow-up was exclusively significantly predicted by any affective disorder at baseline. Its covariates, any affective disorder and any anxiety disorder, were significantly correlated with each other $(r=0.384, \mathrm{p} \leq 0.001)$ but neither of them with education.

To account for the possible association between affective and anxiety disorders with SRH due to its anxiety/depression dimension, we performed additional sensitivity analyses of the two final models, wherein we excluded the anxiety/depression item from the EQ-5D-3 L summary score. These exclusions did not change the significant paths reported in Figs. 1 and 2.

Additionally, following the definition of the World Health Organization defining 'Youth' as the 15-24 age group (http://www. searo.who.int/entity/child_adolescent/topics/adolescent_health/ en/), we examined separately if an age effect can be found. In the younger age group, we found significant paths for posttraumatic stress disorder with SRH and QoL in cross-sectional as well as longitudinal analyses which were not detected before (eTable 4). Further, UHR symptoms were no longer significantly associated with SRH or QoL. Basic symptoms had a significant association with both factors cross-sectionally and with QoL longitudinally (eTable 4, 5)

In the older age group, we found similar cross-sectional associations as in the whole sample (eTable 6). Additionally, any eating disorder and an obsessive-compulsive disorder were longitudinally significantly associated with QoL (eTable 7). Model fit indices for those age-adapted models were generally a bit lower than for the models with the whole sample.

Further we investigated if hallucinations (P4) and delusional ideas (P1-P3) were associated differentially to QoL and SRH. For the cross-sectional model we found an association of delusional ideas 
Table 3

Correlations of predictors for the final cross-sectional model $(\mathrm{N}=2683)$.

\begin{tabular}{|c|c|c|c|c|c|c|}
\hline & Gender ${ }^{a}$ & Education $^{b}$ & $\begin{array}{l}\text { Any } \\
\text { affective } \\
\text { disorder }^{c}\end{array}$ & $\begin{array}{l}\text { Any anxiety } \\
\text { disorderc }\end{array}$ & $\begin{array}{l}\text { Any eating } \\
\text { disorder }\end{array}$ & $\begin{array}{l}\text { Any } \\
\text { somatoform } \\
\text { disorder }^{c}\end{array}$ \\
\hline Age & $\begin{array}{l}r=0.059 \\
p=0.002\end{array}$ & $\begin{array}{l}r=0.252 \\
p \leq 0.001\end{array}$ & $\begin{array}{l}r=0.012 \\
p=0.550\end{array}$ & $\begin{array}{l}r=0.002 \\
p=0.939\end{array}$ & $\begin{array}{l}r=0.011 \\
p=0.474\end{array}$ & $\begin{array}{l}r=0.020 \\
p=0.320\end{array}$ \\
\hline Gender $^{\mathrm{a}}$ & 1.0 & $\begin{array}{l}r=-0.043 \\
p=0.026\end{array}$ & $\begin{array}{l}r=0.029 \\
p=0.179\end{array}$ & $\begin{array}{l}r=0.095 \\
p \leq 0.001\end{array}$ & $\begin{array}{l}r=0.049 \\
p=0.004\end{array}$ & $\begin{array}{l}r=0.042 \\
p=0.026\end{array}$ \\
\hline Education $^{b}$ & & 1.0 & $\begin{array}{l}r=-0.027 \\
p=0.251\end{array}$ & $\begin{array}{l}r=-0.037 \\
p=0.062\end{array}$ & $\begin{array}{l}r=-0.028 \\
p=0.231\end{array}$ & $\begin{array}{l}r=-0.030 \\
p=0.151\end{array}$ \\
\hline $\begin{array}{l}\text { Any affective } \\
\text { disorder }^{c}\end{array}$ & & & 1.0 & $\begin{array}{l}r=0.223 \\
p \leq 0.001\end{array}$ & $\begin{array}{l}r=0.073 \\
p=0.094\end{array}$ & $\begin{array}{l}r=0.273 \\
p \leq 0.001\end{array}$ \\
\hline $\begin{array}{l}\text { Any anxiety } \\
\text { disorder }^{c}\end{array}$ & & & & 1.0 & $\begin{array}{l}r=0.017 \\
\mathrm{p}=0.497\end{array}$ & $\begin{array}{l}r=0.152 \\
p \leq 0.001\end{array}$ \\
\hline $\begin{array}{l}\text { Any eating } \\
\text { disorderc }\end{array}$ & & & & & 1.0 & $\begin{array}{l}r=0.055 \\
p=0.318\end{array}$ \\
\hline $\begin{array}{l}\text { Any somatoform } \\
\text { disorderc }\end{array}$ & & & & & & 1.0 \\
\hline UHR symptoms ${ }^{c}$ & & & & & & \\
\hline
\end{tabular}

Note: UHR: ultra-high risk.

${ }^{\mathrm{a}} 0=$ male, $1=$ female.

${ }^{\mathrm{b}} 0=$ primary school/school for specific needs, $1=$ secondary school, $2=$ high school.

${ }^{\mathrm{c}} 0=$ disorder absent, $1=$ disorder present.

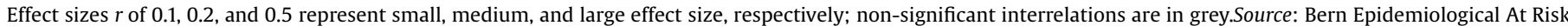
(BEAR) Study (SNF project number: 135,381 and 155,951).

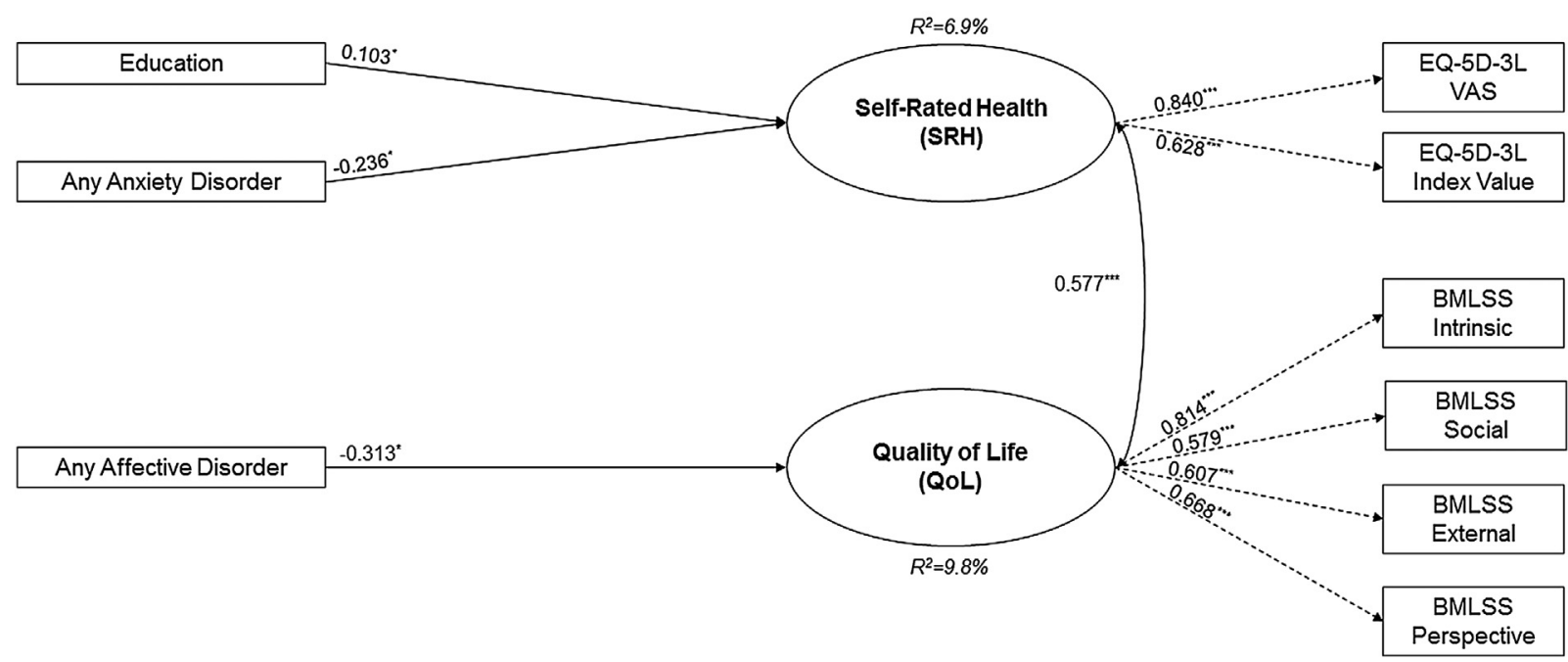

Fig. 2. Results of the trimmed model with non-significant associations removed for the longitudinal data $(\mathrm{n}=829)$.

Model fit indices: $\chi^{2}{ }_{(23)}=0.624, \mathrm{p}=0.132 ; \mathrm{CFI}=0.990 ; \mathrm{TLI}=0.986$; $\mathrm{SRMR}=0.039 ; \mathrm{RMSEA}=0.020(90 \% \mathrm{CI}=0.000-0.037)$.

${ }^{*} \mathrm{p} \leq 0.05,{ }^{* *} \mathrm{p} \leq 0.01,{ }^{* * *} \mathrm{p} \leq 0.001$; standard error (SE) in parentheses; explained variance $\left(\mathrm{R}^{2}\right)$ for each endogenous variable in italics.

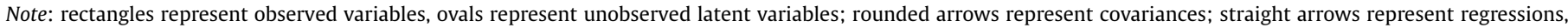
black arrows represent significant regressions; dashed arrows represent factor loadings.

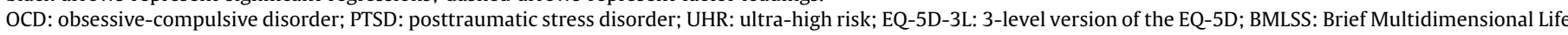
satisfaction Scale. 
on SRH, while hallucinations were not significantly associated with neither QoL nor SRH (eTable 8). For the follow-up data the model did not change.

\section{Discussion}

Our unique community study on the association of sociodemographic variables, CHR symptoms, and mental disorders with QoL and SRH provides important new insights on the effect of UHR and basic symptoms on concurrent, but not prospective QoL and SRH. While age, gender, and education only had small effects, our results also highlight the relationship between mental disorders, particularly affective and anxiety disorders, and QoL and SHR both crosssectionally and longitudinally.

\subsection{Cross-sectional model}

We identified significant cross-sectional associations between our clinical and sociodemographic variables with QoL and SRH, which differed slightly between QoL and SRH, especially regarding the sociodemographic variables.

As expected, sociodemographic variables only played a minor role and had a small effect on SRH but not QoL. In line with earlier studies in both younger [53] and older samples [54,55], we found an association between lower SRH and higher age. The frequent report of females exhibiting lower SRH, especially in physical health $[10,54,56]$, was not supported by our data. On the contrary, in our sample, we found a weak association between lower SRH and male gender. This finding may be partly explained by the fact that in SEM, the association between two variables is estimated while simultaneously controlling for the influence of all other variables in the model. Therefore, the effect of female gender on SRH may have already been taken into account - and thus weakened - by the fact that anxiety and affective disorders as well as CHR symptoms, which all had stronger associations to SRH compared to gender, were positively correlated with female gender. The significant association between a lower educational level and lower SRH is in line with earlier studies [54-58]. Lower $\mathrm{SRH}$ in persons with lower education has been related to fewer positive health behaviours, such as not smoking, observing healthy nutrition, exercising regularly, using sauna/massages, and taking vitamins, but not to a difference in preventive health care usage, such as medical check-ups [58]. While these parameters were not assessed in our study, education was previously shown to be crosssectionally unrelated to help-seeking for mental problems at baseline in the BEAR study [59], thus making it unlikely that an education-related under-use of health care played a role in the SRH-education relationship.

Mental disorders were most strongly associated with both QoL and SRH. Consequently, confirming our hypothesis and in line with previous findings, the largest effects on SRH and QoL were obtained for affective and anxiety disorders [60-62]. Additional significant, yet smaller effects were detected for somatoform disorders on SRH and eating disorders on QoL, despite the rather infrequent report of these disorders (somatoform disorders: $n=27$; eating disorders: $n=12$ ). The association between somatoform disorders and SRH concurs with other community surveys [63]. It might be conveyed by the inclusion of physical symptoms (e.g. pain/discomfort) in the EQ-5D-3 L, which, by definition, are also complained about by persons with somatoform disorders [64]. The effect of eating disorders on QoL supports earlier results on the impact of eating disorders on many domains of QoL [65]. This effect was still discernible against the effect of mood and anxiety disorders that were reported to be predictors of poor QoL in patients with eating disorders [66].
In line with studies showing that QoL is generally poor in CHR samples $[10,11,24]$, we found significant associations of both UHR and basic symptoms with QoL and SRH. Partly confirming our expectations, basic symptoms had a stronger association with SRH than UHR symptoms, whereas for QoL, the association of UHR and basic symptoms did not differ. The sensitivity analyses revealed a stronger association between basic symptoms and SRH as well as between basic symptoms and QoL. Especially for the younger age group there was a strong effect which was also present longitudinally for basic symptoms and QoL. CHR individuals often report high levels of uncertainty and confusion because of the uncontrollable, inexplicable alterations in their mental processes that, consequently, interfere with QoL and SRH [67]. Such a 'basal irritation' resulting from the full insight in and self-experience of impairments in the early illness phase has been described within the conceptual framework of both basic symptoms [67] and the phenomenologically related self-disorders [68] and likely conveys the poor QoL and low SHR associated with basic symptoms $[9,12,13]$. Because basic symptoms and also low-severity UHR symptoms do not necessarily interfere with functioning but are still experienced as 'something not quite right', the stronger effect on SRH compared with QoL might reflect the self-perception of a compromised mental health status. In contrast, QoL might rather be compromised by impaired functioning, which is more likely in the presence of both UHR and basic symptoms [34].

The most noteworthy result, however, is that CHR symptoms, even when they occur rather infrequently and below the threshold for psychosis-risk criteria, have a negative effect on both SRH and QoL in the community, which is independent of the effect of nonpsychotic mental disorders. This emphasises their clinical relevance and the need to address these symptoms not only in specialized services, but in all mental health care $[34,69]$.

The finding of differential effects of delusional ideas on SRH emphasizes the need to address the differential effects of perceptive and non-perceptive psychosis-risk phenomena. Our finding is in line with the finding that attenuated delusional ideas co-occur more likely with functional deficits [70] and supports current critical discussion on the psychopathological value of hallucinatory experiences [71].

\subsection{Longitudinal findings}

Overall, cross-sectional predictors assessed at baseline seem to have few long-lasting effects on both SHR and QoL over approximately three years. Thus, in the longitudinal model, lower $\mathrm{SRH}$ at follow-up was significantly predicted only by lower education and the presence of any anxiety disorder at baseline, while lower QoL at follow-up was significantly predicted exclusively by the presence of any affective disorder at baseline. In doing so, the explained variance of SHR and QoL at follow-up was reduced by more than half in comparison to the crosssectional model.

The negative influence of low baseline educational level, in terms of highest school education, on SRH at follow-up can be assumed to be caused by the great stability of school educational level in a sample with an age range of 16-40 years at baseline, since the majority had already left school at baseline. Thus, this finding supports and extends previous cross-sectional findings on the association between low SHR and low education levels [54,55,57].

The strong effect of affective and anxiety disorders on QoL and SRH might also be associated by a persistence of these disorders, but also supports their earlier reported strong influence on subjective well-being and health evaluation. A similar long-term influence of mental health problems on QoL was found in children and adolescents in the 'BEfragung zum seeLischen WohLbefinden und VerhAlten' (BELLA; English: 'Survey on mental wellbeing and 
behaviour') study [71]. Both our findings and those of the BELLA study emphasize the long-term influence of mental health problems, especially affective and anxiety disorders, on QoL and SRH [72] and the particular persistent burden associated with these disorders [1]. The missing long-term effect of baseline CHR symptoms on QoL and SRH could be explained by the known statelike character of CHR symptoms and the high fluctuation and remission rates of these symptoms [73], with a tendency to be less frequent in older age groups [70]. In our community sample only a small percentage of $2.4 \%$ fulfilled current CHR criteria (including onset or worsening within the past 12 months and at least weekly occurrence in the past month) [34]. A review of psychiatric comorbidity across different stages of schizophrenia showed that anxiety and depressive disorders frequently co-occur throughout the course of the illness, including the prodrome [74], our results further support the idea of depression and/or anxiety being transdiagnostic markers of severity [75] rather than the far more infrequent $\mathrm{CHR}$ criteria being such a transdiagnostic marker.

Overall, our results indicate that, in addition to established mental disorders, CHR symptoms are important treatment targets to improve QoL and SRH over the short-term, while mental disorders, particularly depression and anxiety, should be targeted as early as possible, especially when combined with a low education level, to avoid long-term reductions of QoL and SRH.

\subsection{Strengths and limitations}

Alongside the strengths of our study, such as the large sample size and clinician-rated clinical assessments, the restricted age range (16-40 years at baseline) limits wider generalisability. This age span represents the period when psychotic symptoms and disorders have their onset $[35,36]$, which was the reason for its initial selection [34]. The availability of not only cross-sectional but also longitudinal data is another strength of our study, facilitating a first effort to disentangle cause and effect. Yet, the rather long observation period with a median duration of 39 months might have obscured effects that influence the state-dependent concepts of SRH and QoL over shorter time intervals.

Furthermore, the complex construct of QoL, which still lacks consensus on its definition, may be influenced by additional factors [76] such as self-esteem, mastery, autonomy, and self-efficacy [77] as well as social interactions perceived as stigma experiences [78]. These factors should be additionally considered in future studies.

Another strength of our study is the distinction between QoL and SRH that allowed us to detect differential relationships. If replicated, this distinction may also have important clinical implications, as it suggests tailoring interventions to improve QoL and SRH by targeting the factors most relevant for the respective construct.

\subsection{Conclusion}

Our community findings confirm that CHR symptoms already impose subjective burden and, therefore, are clinically relevant outside clinical samples, already when CHR criteria are not fulfilled. Yet, this negative effect might be restricted to the presence of frequently fluctuating or remitting CHR symptoms, thus not exerting a long-term impact on QoL and SRH. This was different with regard to the frequently untreated, rather persistent or even exacerbating affective and anxiety disorders in the community, which demonstrated both short- and long-term influence on QoL and SRH. The persistent influence of educational level on SRH, however, underlines the importance of information campaigns improving mental health literacy in individuals of all educational levels.

\section{Declaration of Competing Interest}

Drs Michel, Schmidt, Schnyder, Flückiger, and Schultze-Lutter, and Ms Käufeler (MSc) have declared that they have no conflicts of interest in relation to the subject of this study.

Dr Schimmelmann has been a consultant and/or advisor to, or has received honoraria from AstraZeneca, Bristol-Myers Squibb, Eli Lilly, Janssen, Novartis, and Shire.

\section{Funding}

This study was supported by two project-funding grants from the Swiss National Science Foundation (SNFS), grant number 32003B_135381 and 32003B_155951 (to Drs Schultze-Lutter and Schimmelmann).

\section{Acknowledgement}

None.

\section{Appendix A. Supplementary data}

Supplementary data associated with this article can be found, in the online version, at doi:10.1016/j.eurpsy.2019.08.008.

\section{References}

[1] Vigo D, Thornicroft G, Atun R. Estimating the true global burden of mental illness. Lancet Psychiatry 2016;3(2):171-8.

[2] van Knippenberg FC, de Haes JC. Measuring the quality of life of cancer patients: psychometric properties of instruments. J Clin Epidemiol 1998;41 (11):1043-53.

[3] Brekke JS, Long JD. Community-based psychosocial rehabilitation and prospective change in functional, clinical, and subjective experience variables in schizophrenia. Schizophr Bull 2000;26(3):667-80.

[4] Malla A, Payne J. First-episode psychosis: psychopathology, quality of life, and functional outcome. Schizophr Bull 2005;31(3):650-71.

[5] Eack SM, Newhill CE. Psychiatric symptoms and quality of life in schizophrenia: a meta-analysis. Schizophr Bull 2007;33(5):1225-37.

[6] Saarni SI, Viertiö S, Perälä J, Koskinen S, Lönnqvist J, Suvisaari J. Quality of life of people with schizophrenia, bipolar disorder and other psychotic disorders. Br J Psychiatry 2010;197(5):386-94.

[7] Cotton SM, Gleeson JF, Alvarez-Jimenez M, McGorry PD. Quality of life in patients who have remitted from their first episode of psychosis. Schizophr Res 2010;121(1-3):259-65.

[8] MacBeth A, Gumley A, Schwannauer M, Fisher R. Self-reported quality of life in a Scottish first-episode psychosis cohort: associations with symptomatology and premorbid adjustment. Early Interv Psychiatry 2015:9(1):53-60.

[9] Priebe S, Roeder-Wanner UU, Kaiser W. Quality of life in first-admitted schizophrenia patients: a follow-up study. Psychol Med (Paris) 2000;30 (1):225-30.

[10] Ruhrmann S, Paruch J, Bechdolf A, Pukrop R, Wagner M, Berning J, et al Reduced subjective quality of life in persons at risk for psychosis. Acta Psychiatr Scand 2008;117(5):357-68.

[11] Bechdolf A, Pukrop R, Köhn D, Tschinkel S, Veith V, Schultze-Lutter F et at Subjective quality of life in subjects at risk for a first episode of psychosis: a comparison with first episode schizophrenia patients and healthy controls. SchizophrRes 2005;79(1):137-43.

[12] Margariti M, Ploumpidis D, Economou M, Christodoulou GN, Papadimitriou GN. Quality of life in schizophrenia spectrum disorders: associations with insight and psychopathology. Psychiatry Res 2015;225(3):695-701.

[13] Aghababian V, Auguier P, Baumstark-Barrau K, Lancon C. Relationship between insight and self-reported quality of life among schizophrenic patients. Encephale 2011;37(3):162-71.

[14] Brooks R. EuroQol: the current state of play. Health Policy (New York) 1996;37 (1):53-72.

[15] Rohrer JE, Young R, Sicola V, Houston M. Overall self-rated health: a new quality indicator for primary care. J Eval Clin Pract 2007;13(1):150-3.

[16] Mavaddat N, Kinmonth AL, Sanderson S, Surtees P, Bingham S, Khaw KT. What determines Self-Rated Health (SRH)? A cross-sectional study of SF-36 health domains in the EPIC-Norfolk cohort. J Epidemiol Community Health 2011;65 (9):800-6.

[17] Idler EL, Benyamini Y. Self-rated health and mortality: a review of twentyseven community studies. J Health Soc Behav. Behavior 1997;38(1):21-37.

[18] Alonso J, Vilagut G, Adroher ND, Chatterji S, He Y, Andrade LH, et al. Disability mediates the impact of common conditions on perceived health. PLoS One 2013;8(6)e65858. 
[19] Saha S, Chant D, McGrath J. A systematic review of mortality in schizophrenia: is the differential mortality gap worsening over time? Arch Gen Psychiatry 2007;64:1123-31.

[20] De Hert M, Cohen D, Bobes J, Cetkovich-Bakmas M, Leucht S, et al. Physica illness in patients with severe mental disorders. II. Barriers to care, monitoring and treatment guidelines, plus recommendations at the system and individual level. World Psychiatry 2011;2011(10):138-51.

[21] Moreno C, Nuevo R, Chatterji S, Verdes E, Arango C, Ayuso-Mateos JL. Psychotic symptoms are associated with physical health problems independently of a mental disorder diagnosis: results from the WHO World Health Survey. World Psychiatry 2013;12(3):251-7.

[22] Schultze-Lutter F, Michel C, Schmidt SJ, Schimmelmann BG, Maric NP, Salokangas RKR, et al. EPA guidance on the early detection of clinical high risk states of psychoses. Eur Psychiatry 2015;30(3):405-16.

[23] Schaffner N, Schimmelmann BG, Niedersteberg A, Schultze-Lutter F. [Pathways-to-Care for first-episode psychotic patients - an overview of international studies]. Fortschr Neurol Psychiatr 2012;80(2):72-8.

[24] Fusar-Poli P, Rocchetti M, Sardella A, Avila A, Brandizzi M, Caverzasi E, et al. Disorder, not just state of risk: meta-analysis of functioning and quality of life in people at high risk of psychosis. Br J Psychiatry 2015;207(3):198-206.

[25] Watson P, Zhang JP, Rizvi A, Tamaiev J, Birnbaum ML, Kane J. A meta-analysis of factors associated with quality of life in first episode psychosis. Schizophr Res 2018;202:26-36.

[26] Schmidt SJ, Schultze-Lutter F, Schimmelmann BG, Maric NP, Salokangas RKR, Riecher-Rössler A, et al. EPA guidance on the early intervention in clinical high risk states of psychoses. Eur Psychiatry 2015;30(3):388-404.

[27] Hui C, Morcillo C, Russo DA, Stochl J, Shelley GF, Painter M, et al. Psychiatric morbidity, functioning and quality of life in young people at clinical high risk for psychosis. Schizophr Res 2013;148(1-3):175-80.

[28] Granö N, Karjalainen M, Edlund V, Saari E, Itkonen A, Anto J, et al. Health-related quality of life among adolescents: a comparison between subjects at risk for psychosis and other help seekers. Early Interv Psychiatry 2014;8(2):163-9.

[29] Takahashi T, Higuchi Y, Komori Y, Nishiyama S, Nakamura M, Sasabayashi D, et al. Quality of life in individuals with attenuated psychotic symptoms: possible role of anxiety, depressive symptoms, and socio-cognitive impairments. Psychiatry Res 2017;257:431-7.

[30] Mittal VA, Gupta T, Orr JM, Pelletier-Baldelli A, Dean DJ, et al. Physical activity level and medial temporal health in youth at ultra high-risk for psychosis. Abnorm Psychol 2013;122(4):1101-10.

[31] Carney R, Bradshaw T, Yung AR. Monitoring of physical health in services for young people at ultra-high risk of psychosis. Early Interv Psychiatry 2018;12 (2):153-9.

[32] Alonso J, Saha S, Lim CCW, Aguilar-Gaxiola S, et al. The association between psychotic experiences and health-related quality of life: a cross-national analysis based on World Mental Health Surveys. Schizophr Res 2018;201:46-53.

[33] Tomarken AJ, Waller NG. Structural equation modeling: strengths, limitations, and misconceptions. Annu Rev Clin Psychol 2005;1:31-65.

[34] Schultze-Lutter F, Michel C, Ruhrmann S, Schimmelmann BG. Prevalence and clinical relevance of interview-assessed psychosis-risk symptoms in the young adult community. Psychol Med (Paris) 2018;48(7):1167-78.

[35] Kirkbride JB, Fearon P, Morgan C, Dazzan P, Morgan K, Tarrant J, et al. Heterogeneity in incidence rates of schizophrenia and other psychotic syndromes: findings from the 3-center AeSOP study. Arch Gen Psychiatry 2006;63(3):250-8.

[36] McGrath JJ, Saha S, Al-Hamzawi AO, Alonso J, Andrade L, et al. Age of Onset and Lifetime Projected Risk of Psychotic Experiences: Cross-National Data From the World Mental Health Survey. Schizophr Bull 2016;42(4):933-41.

[37] Michel C, Schimmelmann BG, Schultze-Lutter F. Demographic and clinical characteristics of diagnosed and non-diagnosed psychotic disorders in the community. Early Interv Psychiatry 2018;12(1):87-90.

[38] Wang J, Adair CE, Patten SB. Mental health and related disability among workers: a population-based study. Am J Ind Med 2006;49:514-22.

[39] Sheehan DV, Lecrubier Y, Sheehan KH, Amorim P, Janavs J, Weiller E, et al. The Mini-International Neuropsychiatric Interview (M.I.N.I.): the development and validation of a structured diagnostic psychiatric interview for DSM-IV and ICD-10. J Clin Psychiatry 1998;59:22-33.

[40] Schultze-Lutter F, Addington J, Ruhrmann S, Klosterkötter J. Schizophrenia proneness instrument, adult version (SPI-A). Rome: Giovanni Fioriti Editore s.r. 1.; 2007.

[41] McGlashan T, Walsh B, Woods S. The psychosis-risk syndrome. Handbook for diagnosis and follow-up. New York: Oxford University Press; 2010.

[42] Büssing A, Fischer J, Haller A, Heusser P, Ostermann T, Matthiessen PF. Validation of the brief multidimensional life satisfaction scale in patients with chronic diseases. Eur J Med Res 2009;14:171-7.

[43] Janssen MF, Pickard AS, Golicki D, Gudex C, Niewada M, Scalone L, et al. Measurement properties of the EQ-5D-5L compared to the EQ-5D-3L across eight patient groups: a multi-country study. Qual Life Res 2013;22(7):1717-27.

[44] Hinz A, Klaiberg A, Brähler E, König HH. [The Quality of Life Questionnaire EQ 5D: modelling and norm values for the general population]. Psychother Psychosom Med Psychol 2005;56(2):42-8.

[45] Rohde P, Lewinsohn PM, Seeley JR. Comparability of telephone and face-toface interviews in assessing axis I and II disorders. Am J Psychiatry 1997;154 (11):1593-8.

[46] Michel C, Schimmelmann BG, Kupferschmid S, Siegwart M, Schultze-Lutter F. Reliability of telephone assessments of at-risk criteria of psychosis: a comparison to face-to-face interviews. Schizophr Res 2014;53(1-3):251-3.
[47] Brown TA. Confirmatory factor analysis for applied researchers. New York: Guilford Press; 2006

[48] Hipp JR, Bollen KA. Model fit in structural equation models with censored, ordinal, and dichotomous variables: testing vanishing tetrads. Sociol Methodol 2003;33(1):267-305.

[49] Hooper D, Coughlan J, Mullen M. Structural equation modelling: guidelines for determining model fit. Electronic J Business Res Methods. 2008;6:53-60.

[50] Kline RB. Principles and practices of structural equation modelling. New York: Guilford; 2011.

[51] Bentler PM, Bonnet DC. Significance tests and goodness of fit in the analysis of covariance structures. Psychol Bull 1980;88:588-606.

[52] lavaan RosseelY. An r package for structural equation modeling. J Stat Softw 2012;48:1-36. . URL http://www.jstatsoft.org/v48/i02/.

[53] Jörngården A, Wettergen L, von Essen L. Measuring health-related quality of life in adolescents and young adults: swedish normative data for the SF-36 and the HADS, and the influence of age, gender, and method of administration. Health Qual Life Outcomes 2006;4:91.

[54] König HH, Bernert S, Angermeyer MC. [Health Status of the German population: results of a representative survey using the EuroQol questionnaire]. Gesundheitswesen 2005;67(3):173-82.

[55] König HH, Bernert S, Angermeyer MC, Matschinger H, Martinez M, Vilagut G, et al. Investigators. Comparison of population health status in six European countries: results of a representative survey using the EQ-5D questionnaire. Med Care. 2009 2000;47(2):255-61.

[56] Luo N, Johnson JA, Shaw JW, Feeny D, Coons SJ. Self-reported health status of the general adult U.S. Population as assessed by the EQ-5D and Health Utilities Index. Med Care 2005;43(11):1078-86.

[57] Mielck A, Reitmeir P, Vogelmann M, Leidl R. Impact of educational level on health-related quality of life (HRQL): results from Germany based on the EuroQol 5D (EQ-5D). Eur J Public Health 2013;23(1):45-9.

[58] Altenhöner T, Philippi M, Böcken J. [Health behaviour and changes in health behaviour - are education and social status relevant?]. Gesundheitswesen 2014;76(1):19-25.

[59] Michel C, Schnyder N, Schmidt SJ, Ochsenbein S, Schimmelmann BG, SchultzeLutter F. Functioning mediates help-seeking for mental problems in the general population. Eur Psychiatry 2018;54:1-9.

[60] Brenes GA. Anxiety, depression, and quality of life in primary care patients. Prim Care Companion J Clin Psychiatry 2007;9(6):437-43.

[61] Fink P, Ørnbøl E, Christensen KS. The outcome of health anxiety in primary care. A two-year follow-up study on health care costs and self-rated health. PLoS One 2010;5(3):e9873.

[62] Ambresin G, Chondros P, Dowrick C, Herrman H, Gunn JM. Self-rated health and long-term prognosis of depression. Ann Fam Med 2014;12(1):57-65.

[63] Mewton L, Andrews G. Poor self-rated health and its associations with somatisation in two Australian national surveys. BMJ Open 2013;3(6)e002965.

[64] Rasmussen NH, Bernard ME, Harmsen WS. Physical symptoms that predict psychiatric disorders in rural primary care adults. J Eval Clin Pract 2008;14 (3):399-406.

[65] de la Rie SM, Noordenbos G, van Furth EF. Quality of life and eating disorders. Qual Life Res 2005;14(6):1511-22.

[66] Martín J, Padierna A, Loroño A, Muñoz P, Quintana JM. Predictors of quality of life in patients with eating disorders. Eur Psychiatry 2017;45:182-9.

[67] Klosterkötter J. The meaning of basic symptoms for the genesis of the schizophrenic nuclear syndrome. Jpn J Psychiatry Neurol 1992;46(3):609-30.

[68] Schultze-Lutter F, Theodoridou A. The concept of basic symptoms: its scientific and clinical relevance. World Psychiatry 2017;16(1):104-5.

[69] Ruhrmann S, Schultze-Lutter F, Klosterkötter J. Probably at-risk, but certainly ill - advocating the introduction of a psychosis spectrum disorder in DSM-V. Schizophr Res 2010;120(1-3):23-37.

[70] Schimmelmann BG, Michel C, Martz-Irngartinger A, Linder C, Schultze-Lutter F. Age matters in the prevalence and clinical significance of ultra-high-risk for psychosis symptoms and criteria in the general population: findings from the BEAR and BEARS-Kid studies. World Psychiatry 2015;14:189-97.

[71] Zhang T, Xu L, Tang Y, Cui H, Wei Y, Tang X, et al. Isolated hallucination is less predictive than thought disorder in psychosis: insight from a longitudinal study in a clinical population at high risk for psychosis. Sci Rep 2018;8(1):13962.

[72] Otto C, Haller AC, Klasen F, Hölling H, Bullinger M, et al. BELLA study group. Risk and protective factors of health-related quality of life in children and adolescents: results of the longitudinal BELLA study. PLoS One 2017;12(12) e0190363.

[73] Michel C, Ruhrmann S, Schimmelmann BG, Klosterkötter J, Schultze-Lutter F Course of clinical high-risk states for psychosis beyond conversion. Eur Arch Psychiatry Clin Neurosci 2018;268(1):39-48.

[74] Buckley PF, Miller BJ, Lehrer DS, Castle DJ. Psychiatric comorbidities and schizophrenia. Schizophr Bull 2009;35(2):383-402.

[75] Schultze-Lutter F, Klosterkötter J, Gaebel W, Schmidt SJ. Psychosis-risk criteria in the general population: frequent misinterpretations and current evidence. World Psychiatry 2018:17(1):107-8.

[76] Post MW. Definitions of quality of life: what has happened and how to move on. Top Spinal Cord Inj Rehabil 2014;20(3):167-80.

[77] Zissi A, Barry MM, Cochrane R. A mediational model of quality of life for individuals with severe mental health problems. Psychol Med (Paris) 1998;28:1221-30.

[78] Yanos PT, Rosenfield S, Horwitz AV. Negative and supportive social interactions and quality of life among persons diagnosed with severe mental illness. Community Ment Health J 2001;37:405-19 a. 